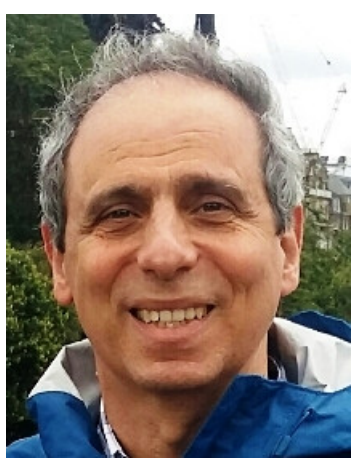

\title{
Shôn Ffowcs Williams (1935-2020) - a life devoted to Acoustics
}

John Eirwyn Ffowcs Williams was born in Wales on 25 May 1935 and passed away, also in his native country, on 12 December 2020. He was known among his friends as Shôn, a Welsh form of John. He left a very deep mark in acoustics, having made important contributions to the development of not only aeroand hydro-acoustics, but also in fields like anti-sound, active control of flow instability, and bio-engineering. A notable feature of Shôn's papers, which have been a source of inspiration for researchers in acoustics for about 60 years, is that the reader knows in advance that he/she will find a text where the physics is clearly explained while the mathematics, even if it might become eventually complex (as it frequently will), starts from basic principles, stated in a "simple to understand" and in an extremely elegant way - which is, indeed, carried on to the very end.

Shôn did his Ph. D. at the University of Southampton (1961) under the supervision of E. J. Richards - the founding editor of the Journal of Sound and Vibration and who, in Shôn's own words (JSV, 190(3), pp. 387-398, 1996) "was involved at the birth of aeroacoustics". Shôn was thus unequivocally (and irreversibly) involved with this subject. In his thesis he tackled a number of issues regarding Doppler factors as modifiers of the acoustic intensity due to the noise of turbulent jets (Phil. Trans. Roy. Soc. A 255 (1061), pp. 469-503, 1963). Notably, he showed that, as jet velocity increases, the Doppler factor which appears (as he had demonstrated) with an inverse fifth power in the acoustic intensity and would lead, when combined with Lighthill's eighth power velocity law to the result that the radiated intensity of supersonic jets increases with the cube of the velocity (i.e., that the acoustic power radiated becomes proportional to the jet's mechanical power).

One of his most celebrated results is the so-called "Ffowcs Williams-Hawkings equation" (Phil. Trans. Roy. Soc., A 264 (1151), pp. 312-342, 1969), that was obtained with his $\mathrm{Ph}$. D. student David L. Hawkings and addresses the role of moving surfaces in the generation of sound. While the paper is an outstanding example of the mathematical elegance mentioned above, the theory became paramount for the description of the sound generated by propellers and moving bodies in general.

In 1968, he presented a video, along with Sir James Lighthill, one of the founders of the International Institute of Acoustics and Vibration (IIAV), explaining the basics of "Aerodynamic generation of sound". It runs for almost 45 minutes and was produced by the US National Committee for Fluid Mechanics Films; it can be watched at this Youtube page (click). Viewers will note that the first half goes at a relaxed pace while the second one is faster. This is because the presenters were informed, after the first half was shot, that half the film had already been used. So, they hurried up to make the rest of the lecture fit in the film available. At the cited website, one of the comments reads: "This is as amazing as having Newton and Leibniz teaching you Calculus". I have to agree.

His research work was mostly industry motivated. He was the co-founder of the Cambridge-based start-up company Topexpress Ltd (1978), and during the development of the Concorde, he was put in charge of the noise panel of experts for that airplane.

His many achievements are listed, e.g., at this University of Cambridge page (henceforth called [1]) and at Wikipedia (called [2]), and also in some of the papers presented in the session in his honor at the ICSV22 in Florence (2015). This special session (session T03.SS05: Professor Shôn Ffowcs Williams and Aeroacoustics), organized by Kenneth Brentner, Yueping Guo, Maria Heckl, Lixi Huang, and Xiaoyang Huang, was devised to celebrate his 80th birthday. It included 17 papers, written by his former students, by their students and by friends and admirers. Of these, three papers were specifically on Shôn and the others were technical papers on aeroacoustics and related subjects. The presentations on 14 and 15 July were followed by gastronomical events: a private dinner (at the simple but excellent "Giglio Rosso") on the 14th, and the Conference Banquet, with an unforgettable presentation of Italian music, on the 15 th, when his birthday was announced by the ICSV22 President, Eleonora Carletti. The 17 papers were republished in a booklet with additional material, including photos of the events at ICSV22 and some taken on previous occasions, and a "scientific genealogy", i.e., a list of Shôn's students and, in some cases, their students.

Shôn was awarded the AIAA (American Institute of Aeronautics and Astronautics) Aero-acoustics Medal (1977), the Rayleigh Medal by the UK Institute of Acoustics (1984), the Médaille Étrangère by the French Acoustic Society (1989), and the Sir Frank Whittle Medal by the Royal Academy of Engineering (2002). He was elected a Fellow of the Royal Academy of Engineering (1988), a foreign member of the US National Academy of Engineering (1995), a Fellow of the Royal Aeronautical Society, of the Royal Society of Arts, of 


\section{Editor's Space}
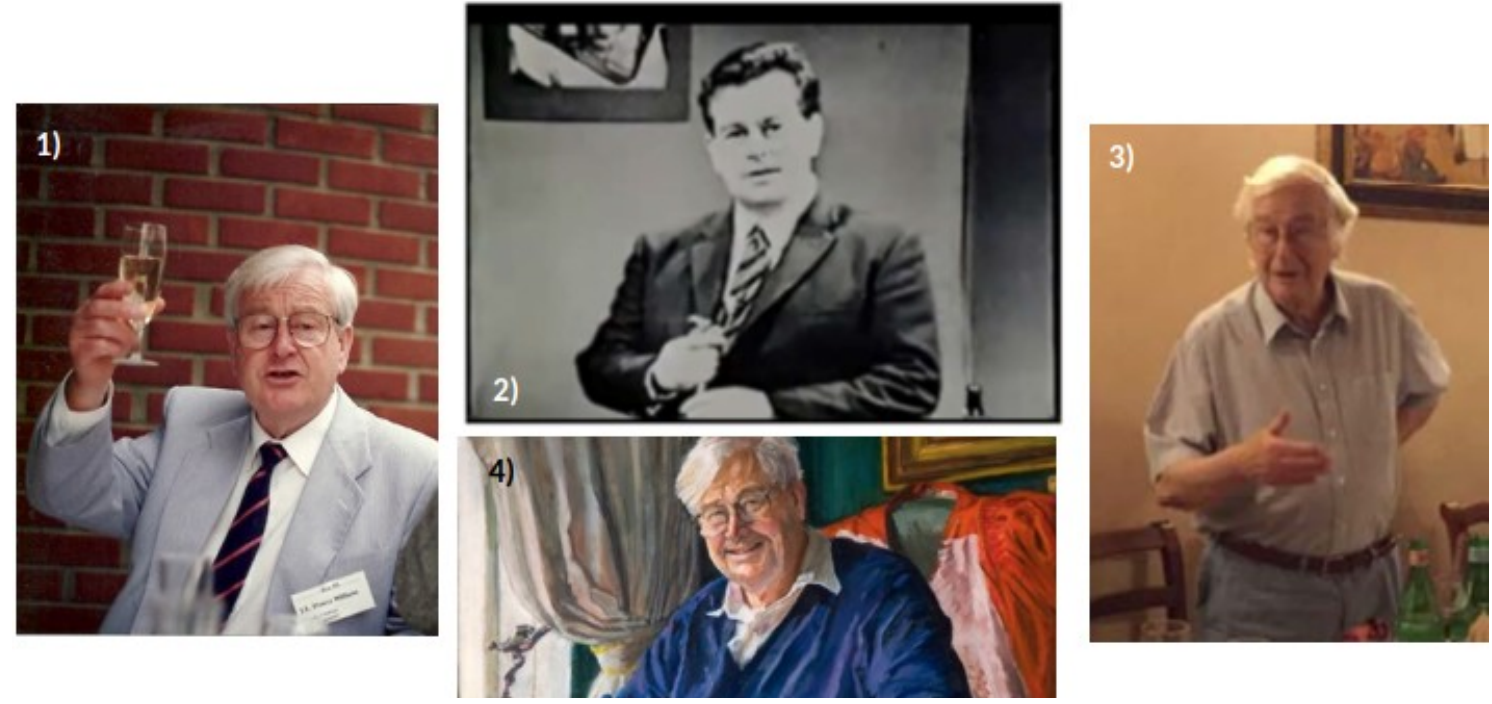

Figure 1. Shôn Ffowcs Williams: 1) at the 15th ICA, Trondheim, 30 June 1995; 2) in the Lighthill \& Ffowcs Williams movie (1968); 3) at the Giglio Rosso, Florence, 14 July 2015; 4) portrait by Louise Riley-Smith [1] (1999; detail).

the Institute of Physics of the Acoustical Society of America and of the AIAA [1,2].

Shôn Ffowcs Williams co-authored two books: Sound and Sources of Sound, with Ann Dowling (Ellis Horwood, 1983) — an undergraduate textbook used frequently by graduates and Modern methods in analytical acoustics, with Ann Dowling, David Crighton, Manfred Heckl and Frank Leppington (Springer-Verlag, 1992), in which he is the author of four chapters.

When he retired in 2002, he was the longest-serving professor at the University of Cambridge, which he joined in 1972.

He was noted for persuading good students to tackle interesting problems [2]. Shôn had a total of 37 Ph. D. students, including David Crighton, Dame Ann Dowling and the five organizers of the special ICSV22 session (K. Brentner, Y. Guo, Maria Heckl, L. Huang and X. Huang), to cite just a few (I apologize to all others for not citing them explicitly!). They all refer to him as an outstanding and friendly supervisor. In the words of Dame Ann Dowling [1]: "Shôn was creative and inventive. (...) He was inspiring and fun as $\mathrm{PhD}$ supervisor, colleague and friend and will be greatly missed by all who knew him."

Special issues in his honor are being prepared in the International Journal of Aeroacoustics and the Journal of Sound and Vibration. A memorial service is intended to take place at Emmanuel College, Cambridge, in 2022. This editorial is presented as an additional homage of IJAV and the IIAV to Shôn Ffowcs Williams, someone who helped us to see more clearly in aeroacoustics (and in other fields as well), and notably in the description of sound sources. With thanks to: Anne Ffowcs Williams, Maria Heckl and Lixi Huang.

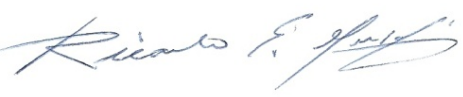

Ricardo E. Musafir

Former IIAV Director (2010-2014, 2016-2020) 